\title{
A Perspective on the Idea of 'Complicity'
}

TOM KIEREN

University of Alberta (Canada)

At a workshop session at a folk concert that I attended, three bands were playing. As is typical of such sessions each band was to take a turn and play one of their tunes. Members of the other groups tended to play along mostly in the background. And so it started here-the Bill Hilly Band played a tune and some of the members of the other 2 bands played along in the background-nice. Then it was the Waybacks' turn. After a few bars the gregarious members of the Bill Hilly Band not only joined in, but were inspired by the Waybacks' music and lyrics to add their own unique touches. With this, the Waybacks also altered the way they were playing in response, and now the Co-dependents joined in, adding their unique ideas. While the original tune/idea was not lost, a whole new brilliant musical interpretation arose that simply would not have existed in other circumstances.

For me this was complicity in action. Where was the song/knowledge? In the performers' heads? No. It clearly emerged in the inter-action. What "caused" this phenomenon? Cause, in its usual sense, is not the right word here. In this situation, I observed that the actions of each group were complicit in, but did not cause the further actions of the others or the collective. Beyond that, each group could be observed as listening to the others and, in so doing, responding anew. While these actions and their aural results were determined by the capabilities of the individual players and groups-they were codetermined by the actions of others as well as the setting in which 
they took place in a manner which could not be predicted ahead of time.

What has influenced me as I have come to observe folk concerts and, more importantly, education in classrooms in this manner? Firstly, it is just such observation (over the last 30 years), of mathematics knowing and understanding of children and adolescents as a conscious activity that has focused my attention on the non-linear, dynamical, and recursive natures of these phenomena. In so doing I have come to use the word complicity (or coimplicity) as the functioning of a system with many distinct parts not only functioning together but in such a way that the very nature of the functioning of each influences and is influenced by the functioning of the others. Because I was studying conscious activity, I have recently resonated with arguments by Merlin Donald (2002) or by Francisco Varela (e.g., Varela, Thompson, \& Rosch, 1991), who suggest that such activity is not simply emergent from brain functioning, but occurs in inter-action and is co-determined both by the individual's structure and the whole setting with others in which they are observed. Within such a complicit view, knowledgesuch as the song heard in my story above-is not viewed as a static phenomenon, but as a bringing forth of a world of significance with others (cf. Maturana and Varela, 1987).

How might this be seen to work? Briefly, I will use a model of such complicit knowing, adapted from the work of Elaine Simmt (Kieren \& Simmt, 2002) to frame my response. (I have used this model to observe and analyze mathematics knowing in inter-action.) There are three primary terms in this model: the individual (I); the others/otherness $(O)$; and the interaction. There are three primary knowing pathways that, for me, constitute the possibility to observe such knowing as coemerging complicitly with others. In the first pathway let us imagine $O$ to be a teacher with materials. It is typical to observe the teacher in some way using materials to provide an opportunity for $I$ to act. What is significant in this model is that this teacher's actions are not causative. Teacher actions provide possibilities that must be taken up and transformed by I for her own use in knowing. The second pathway shows $I$ in some way in interaction with herself. That is, I makes some form of re-presentation of her ideas (which may or may not be externally observable) that she may then take up and transform/ use for her own knowing purposes. The third pathway arises just when $I$ in her knowing act makes some externally observable re-presentation or utterance in interaction with $O$ (or the teacher/materials in this example). The teacher may take up this utterance and, through this, transform her own thinking about the situation, her actions, and even the nature of the materials in use.

And so these reciprocal and indeed frequently co-recursive cycles of $I / O$ (and $I / I$ ) inter-action may continue. Notice that neither the actions of the teacher nor those of the Is cause the others to act. Only the structures of the 
individuals (learner or teacher) or the structures of the materials and the environment allow them to "act." Thus there is no "instruction" in the causative sense in this model. But any act by any person in the space can change the knowing of the others; the collective knowing of $I / O$ group, the sphere of behavioural possibilities in the space (and thus the living nature of that space itself), as well as the observable cognitive domain in the setting and indeed possibly in the larger cultural sense as well.

What are the consequences of seeing lived experiences, particularly educational ones, through the lens of this view of complicity? Here are a few brief observations:

- Complicity is an observable phenomenon of an implicate order (implicit-as opposed to explicit or random-and dynamical, non-linear, not predictable in any detail before it is enacted). But it is not some mysterious, non-scientific or simply spiritual phenomenon. Using complicity ideas in observation allows one to avoid being caught in the duality of holistic or reductionist observations or analyses;

- A complicit situation, such as knowing in a classroom, deserves study at both the level of the individual knower and the whole class (likely at the same time). As argued by Varela (see Rudrauf et al., 2005) there is 'upward' emergent pressure from individual knowers as well as 'downward' collective pressure from collective knowing of the group and the constraints and boundary conditions of the space. It follows that collective knowing and understanding can be studied by modeling their emergence from individual knowing but also from observing just the ways in which boundary conditions (such as the diversity and redundancies of classroom actions / utterances or decentralized control features) occasion such knowing.

- Classroom settings in which such complicity may be best observed are ones in which the linear logic of instruction for achieving prespecified goals has been exchanged for the circular or recursive logic of a teaching co-developing activity, Specifically, this calls for observing teaching as the provision of possibilities for appropriate knowing.

This view of complicity, even if developed beyond the sketch offered here, as well as the related consequential observations, are necessarily incomplete. They arise as one part in a multiversal view of complicit educational phenomena and may not even entertain other relevant ideas about complicity and their applications in observing classroom knowing.

\section{References}

Donald, Merlin. 2002. A mind so rare: The evolution of human consciousness. New York: W.W. Norton. 
Kieren, Thomas, and Elaine Simmt. 2002. Fractal filaments: A simile for observing collective mathematical understanding. In Proceedings of 24th annual meeting of Psychology of Mathematics Education Columbus, OH: ERIC Clearing House for Mathematics Science and Environmental Education.

Maturana, Humberto, and Francisco Varela. 1987. Tree of knowledge . Boston: Shambhala.

Rudrauf, D., A. Lutz, D. Cosmelli, J-P. laChaux, and M. le VanQuyen. 2005. From autopoiesis to neurophenomenology: Francisco Varela's exploration of the biophysics of being. Biological Research 36: 27-65.

Varela, Francisco, Evan Thompson, and Eleanor Rosch. 1991. The embodied mind. Cambridge: MIT Press.

\section{About the Author}

Tom Kieren is Professor Emeritus of Mathematics Education, Department of Secondary Education, University of Alberta. Tom has a long standing research interest in complexity, particularly focused on the consequences of co-emergence for mathematics education and the conditions for emerging collective understanding in classrooms.

(C) Copyright 2005. The author, Tom Kieren, assigns to the University of Alberta and other educational and non-profit institutions a non-exclusive license to use this document for personal use and in courses of instruction provided that the article is used in full and this copyright statement is reproduced. The authors also grant a non-exclusive license to the University of Alberta to publish this document in full on the World Wide Web, and for the document to be published on mirrors on the World Wide Web. Any other usage is prohibited without the express permission of the authors. 